\title{
Somatic Pairing: An Alternative for the Development of Cancer and other Hereditary Diseases
}

\author{
S. A. Faruqi', R. C. Miller ${ }^{2}$ and J. S. Noumoff' \\ 'Gynecologic Oncology Research Laboratories, Crozer-Chester Medical Center, \\ Ambulatory Care Pavilion $\$ 332$ One Medical Center Boulevard, \\ Upland, Pa 19013, U.S.A. \\ ${ }^{2}$ Medigen Clinical Laboratories, 907 Pine Street Philadelphia,
} Pa 19107, U.S.A.

Accepted October 27, 1994

On the basis of his studies on retinoblastoma, Knudson (1971) proposed that the loss of alleles of the same tumor suppressor gene is responsible for the onset of cancer. Today, already described are some 32 cancers and some 60 other hereditary anomalies (Sager 1989, Cooper and Schmidtke 1989, Mitelman 1991, McKusick 1992, Borgaonkar 1994) where loss of one or more set of alleles is responsible for the disease. However, a simple "two hit" mutation theory as proposed by Knudson (1971) would not always apply for two reasons. First, it is already known that many tumors involve more than two alleles thus a "two hit" mechanism would not be able to target all of the involved genes, either through mutation or deletion (Sager 1989). Secondly, even in retinoblastoma, which has been proven to involve only two tumor suppressor genes (Cavenee et al. 1983, Dryja et al. 1984), studies on the loss of heterozygosity (LOH) demonstrate that two-thirds of tumors show non-disjunction or mitotic recombination rather than the structural deletion. Moreover, Murphee and Benedict (1984) concluded from Restriction Fragment Length Polymorphism (RFLP) analysis of retinoblastoma that a chromosomal mechanism (rather than mutation) plays a major role in the second tumorigenic event. An alternative theory to the origin of LOH has been proposed resulting in a series of papers (Knudson 1977, 1985, Fearon et al. 1984, 1987, Benedict et al. 1983, Orkin et al. 1984, Reeve et al. 1984, Hansen et al. 1985, Seizinger et al. 1986, Dracopoli et al. 1989, James et al. 1989, Scrable et al. 1987, Yokota et al. 1987, Fong et al. 1989) theorizing on mitotic crossover. However, the actual demonstration of chromatid exchange has been lacking. In the present study, we present final evidence to demonstrate that mitotic chromosomal pairing as well as homologous chromatid exchange are present in normal human cells and therefore provide a mechanism for genetic recombination, the origin of homozygosity and hence the origin and evolution of cancer and other hereditary diseases.

\section{Materials and methods}

All the materials were obtained from the amniotic fluid cultured on coverslips and harvested in situ or blood samples cultured in T 25 flasks. Chromosomes were banded using trypsin from Difco Laboratories and Wrights Giemsa prepared in our laboratory.

\section{Results}

Our results demonstrate numerous cases of chromosomal pairing in mitosis, both in blood and amniotic fluid cultures with $46, \mathrm{XX}$ or $46, \mathrm{XY}$ chromosomes. We present here six examples 
showing different states of chromosomal pairing in mitosis. Fig. 1 shows close association of chromosome numbers 10,11, 13, 14, 15, 19, 21 and 22 while Fig. 2 demonstrates a band to band pairing in chromosome \#1. The chiasmata formation of both arms is shown for chromosomes $\# 12,7$ and 15 (Figs. 3-5). The chiasmata formation has the same configuration as in meiosis in all the three cases above. The attachment of chromatids of the homologous pairs, even after physical disturbance created by colchemid and hypotonic, is indicative that the chromatids have been through the physical exchange and the chromosomes are similar to metaphase pairs of meiosis. Finally, Fig. 6 shows a pair of chromosomes 11 with mitotic cross over where the $p$ arm of one chromatid of one of the chromosomes is clearly fused with the $q$ arm of the other homologue's chromatid. The two remaining broken arms are still naked and unattached. This is positive proof of chromatid exchange between homologous chromosomes in mitosis.

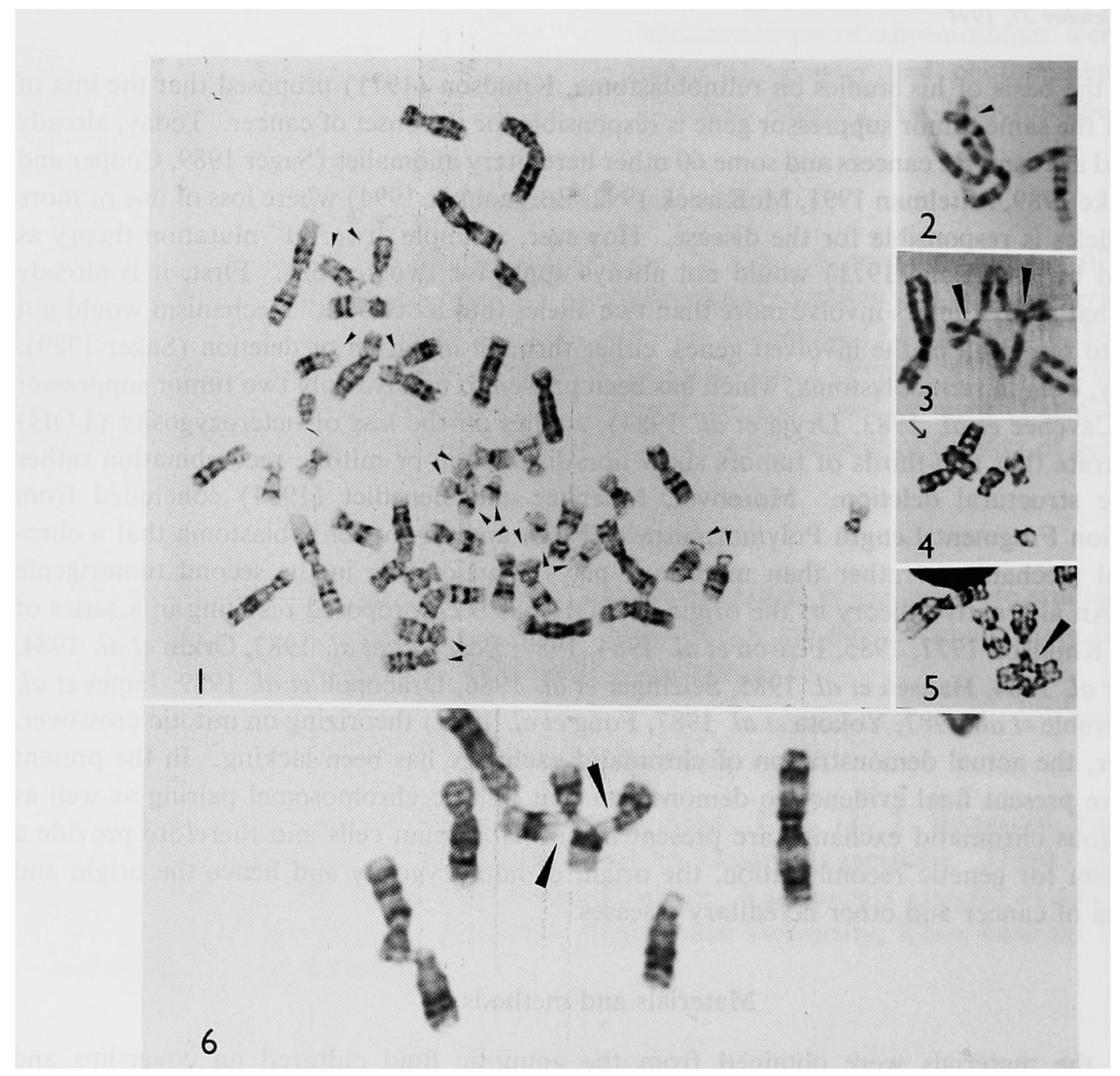

Figs. 1-6. 1. A cell from amniotic culture showing close association of chromosomes \#10, 11, $13,14,15,19,21$ and 22 in metaphase. Some dislocation of chromosomes after colcemid and hypotonic treatment is expected. 2. A cell from amniotic culture at 550 band level, showing band to band pairing of chromosome \#1. 3. Chiasma formation in chromosome \#12 from amniotic culture which has the configuration exactly like meiosis. 4. Chiasma formation in chromosome \#7 from blood culture. 5. Chiasma formation in chromosome \#15 from blood culture. 6. A pair of chromosome 11 from amniotic culture showing mitotic crossover between a pair of chromatids. Note that the $\mathrm{p}$ arm of the chromatid of one chromosome has fused with the $\mathrm{q}$ arm of the chromatid of the other chromosome. The other two broken ends have not fused as yet and their naked ends are visible. 


\section{Discussion}

Ordinarily, recombination is a mechanism known in sexual reproduction through the process of meiosis where chromosomes pair and chromatids exchange parts. In mitosis, however, chromosomes generally do not pair and consequently all the cells are duplicated precisely and thus inherited with the same unaltered genome. However, Stevens $(1907,1908)$ demonstrated that somatic pairing of chromosomes takes place in Drosophila. Pontecorvo and Kafer (1958) through intensive studies on the fungus Aspergillus nidulance also demonstrated mitotic recombination. Similarly, mitotic chromosomal pairing has been shown to occur in certain plant (Huskins 1948, Wilson and Cheng 1949) and animal (Stern 1936, Cohen et al. 1972, Heneen and Nichols 1972) species including man, in both normal unbanded chromosomes (German 1964) and banded tumor cell chromosomes (German et al. 1965, Welter et al. 1967, Chaganti et al. 1974). Yet the importance and frequency of this phenomenon was virtually ignored by all but a few plant evolutionists (Sharma and Sharma 1959). Radman and Kinsella (1980) were the first to propose somatic recombination resulting in the homozygosity of a heterozygous allele, leading to tumorigenesis.

With the introduction of molecular techniques, several examples of possible recombination in various cancers have been proposed (Cavenee et al. 1983, Fearon et al. 1984, German 1964). Groden et al. (1990) demonstrated somatic recombination in a proliferative tissue, while Gregory et al. (1991) have presented a strong argument for somatic recombination in their study of Prader-Willi syndrome. Similarly partial uniparental disomy for chromosome $15 q$ is proposed for Bloom syndrome (Woodage et al. 1994).

Wake and Wilson $(1979,1980)$, and others (Upcroft et al. 1980, Volkert and Young 1983, Kucherlapati 1989) using viral substrates showed that somatic mammalian cells have all of the enzymes required to catalyze homologous recombination, while Mehra and Dhiman (1986a, b), and Mehra and Kumari (1986) were able to induce chromosomal pairing in-vivo in the Allium roots with the derivatives of purines and pyrimidines.

Muller (1940), based on his studies on Drosophila proposed that the chances of exchange between chromosomes which are closer are greater than the chances between those chromosomes which lie farther apart. Arnoldus et al. (1989), using centromeric probes demonstrated somatic pairing of chromosome \#1 in interphase nuclei of human cerebellum. Mosgoler et al. (1991) using serial electron micrography in the three dimensional reconstruction of all 46 human chromosomes, noted the tendency of chromosomes of similar sizes to cluster together, the smaller moving towards the center and the larger towards the periohery. The observation of Mosgoler et al. (1991) is confirmed in Fig. 2, where a close association of eight pairs of chromosomes is maintained even after treatment with colchemid and hypotonic.

The genetic aspect of chromosome pairing is well documented and understood in meiosis (Riley and Chapman 1958, Chheda and Harlan 1962, Faruqi 1964, Faruqi and Quraish 1979, Quraish and Faruqi 1979). Such a genetic mechanism, however, is still not understood in mitosis. However, the presence of homologous chromatid exchange in Bloom syndrome and nonhomologous exchange in Fanconi anemia (Schroeder and German 1974) does imply the involvement of such a genetic mechanism. Thus, a very small change of either environment (Mehra 1986) or gene, might result in some degree of homologous chromosome pairing and exchange of parts between the chromatids of homologous chromosomes.

The data in the present study clearly shows for the first time band to band pairing, chiasma formation as well as incomplete chromatid exchange (Figs. 1-6) in normal human blood and amniotic cells, providing validity to mitotic crossover as seen at the chromosomal level. If one considers the data currently presented, along with the results of LOH and RFLP analyses, a possible alternative to the "two hit" of Knudson's hypothesis becomes evident, not only for 
cancers but for most of the genetic diseases.

The reason that somatic pairing and somatic chromatid exchange in normal tissue with banded chromosomes had not yet been documented is that only in the recent past has coverslip culture and in-situ harvest of amniotic fluid and products of conception become common. Secondly, in the clinical diagnostic lab such an anomaly with no apparent clinical consequence is neither sought nor understood and consequently neglected.

Up until now, a clear exchange of chromatids between two homologous chromosomes had never been reported in the normal human cell, since the data described previously (German 1964) dates to the "pre-banding" era. The only evidence of possible chromatid exchange comes from the work of Chaganti et al. (1974) who using BrdU in the blood culture of Bloom's syndrome patients found the evidence from which it could be concluded that chromatid exchange between homologous pairs should have taken place. The chromatid exchange in chromosome $\# 11$, shown here (Fig. 6), is a clear demonstration of this phenomena in normal human amniotic cell. Since the division is basically mitotic, the centromere of each chromosome divides to form four chromatids. During migration at anaphase, there is a $50 \%$ chance for two chromatids with similar mutated alleles (or deletion) to be inherited together. This event would produce partial uniparental disomy and consequently homozygosity and start of the disease.

Today we believe that almost all cancers owe their origin to some genic malfunction. This malfunction could originate either through mutation or deletion occurring twice in the same region as has been shown in retinoblastoma (Knudson 1971), small cell lung cancer (WhanPeng et al. 1982), as well as many other cancers and hereditary diseases (Cooper and Schmidtke 1989, Rowley 1989), or through structural changes such as described in leukemia (Nowell and Hungerford 1960).

We propose somatic pairing of homologous chromosomes during the mitotic cell division as an additional mechanism resulting in partial uniparental disomy, the homozygosity of either the defective allele or a deletion as an additional mechanism to explain the etiology of both genetic diseases as well as cancers.

\section{Summary}

Until recently, the importance of mitotic crossover between homologous chromosomes and its role in the etiology and evolution of malignancy had not been realized. This was in part secondary to the fact that the only direct evidence for chiasma formation in normal human tissue came from the "pre-banding era." An actual physical exchange between the chromatids of a homologous pair of chromosomes had not been documented. To date, whatever direct cytogenetic evidence that mitotic crossover exists comes from cancer cells with altered genomes. We report for the first time, demonstration of band to band chromosomal pairing, chiasma formation and chromatid exchange physically visible in normal human blood and amniotic cell culture. With this phenomenon now documented, its role in the malignancy and origin of partial uniparental disomy and consequently in the origin of other hereditary diseases can be relevantly hypothesized.

\section{References}

Arnoldus, E. P. J., Peters, A. C. B., Bots, G. T. A.M., Raap, A. K. and Ploeg, M. Van Der. 1989. Somatic pairing of chromosome 1 centromeres in interphase nuclei of human cerebellum. Human Genet. 83: 231-234.

Benedict, W. F., Murphee, A. L., Banerjee, A., Spina, C. A., Sparkes, M. C. and Sparkes, R. S. 1983. Patient with 13 chromosome deletion: Evidence that retinoblastoma gene is a recessive cancer gene. Science 219: $973-975$. 
Borgaonkar, D. S. 1994. Chromosomal Variation in Man. Wiley-Liss, N.Y. pp. 1116.

Cavenee, W. K., Dryja, T. P., Phillip, R. A., Benedict, W. F., Godbout, R., Gallie, B. L., Murphee, A. L., Strong, L. C. and White, R. L. 1983. Expression of recessive alleles by chromosomal mechanisms in retinoblastoma. Nature 305: 779-784.

Chaganti, R., Schonberg, S. and German, J. 1974. A many fold increase in sister chromatid exchanges in Bloom's syndrome lymphocytes. Proc. Natl. Acad. Sci. U.S.A. 71: 4508-4512.

Chheda, H. R. and Harlan, J. R. 1962. Mode of chromosome association in Bothriochloa hybrids. Caryologia 15: 461476.

Cooper, D. M. and Schmidtke, J. 1989. Review article. Diagnosis of genetic disease using recombinant DNA. Second Edition. Hum. Genet. 83: 307-334.

Cohen, M. M., Enis, P. and Pfeifer, C. G. 1972. An investigation of somatic pairing in the muntjack (Muntiacus muntjak). Cytogenetics 11: 145-152.

Dracopoli, N. C., Harnett, P., Bale, S. J., Stanger, B. Z., Tucker, M. A., Housman, D. E. and Kefford, R. F. 1989. Loss of alleles from distal short arm of chromosome 1 occurs late in melanoma tumor progression. Proc. Natl. Acad. Sci. U.S.A. 86: 4614-4618.

Dryja, T. P., Cavenee, W., White, R., Rapaport, J. M., Peterson, R., Albert, D. M. and Bruns, G. A. P. 1984. Homozygosity of chromosome 13 in retinoblastoma. N. Eng. J. Med. 310: 550-553.

Faruqi, S. A. 1964. Cytogenetical studies of the Bothriochloa intermedia complex. Cytologia 29: 280-297.

- and Quraish, H. B. 1979. Studies on Libyan grasses I. Cytogenetics and distribution of aneuploid Hyparrhenia hirta. Caryologia 31 : 305-314.

Fearon, E. R., Hamilton, S. R. and Vogelstein, B. 1987. Clonal analysis of human colorectal tumors. Science 238: 193197.

-, Vogelstein, B. and Feinberg, A. P. 1984. Somatic deletion and duplication of genes on chromosome 11 in Wilm's tumours. Nature 309: 193-197.

Fong, C. T., Dracopoli, N. C., White, P. S., Merrill, P. T., Griffith, R. C., Housman, D. E. and Broduer, G. M. 1989. Loss of heterozygosity for the short arm of chromosome 1 in human neuroblastomas: correlation with $\mathrm{N}$-myc amplification. Proc. Natl. Acad. Sci. U.S.A. 86: 3753-3757.

German, J. 1964. Cytological evidence for crossingover in vitro in human lymphoid cells. Science 144: $298-301$.

- Archibald, R. and Bloom, D. 1965. Chromosomal breakage in a rare and probably genetically determined syndrome in man. Science 148: 506 507.

Gregory, C. A., Schwartz, J., Kirkilionis, A. J., Rudd, N. and Hamerton, J. L. 1991. Somatic recombination rather than uniparental disomy suggested as another mechanism by which genetic imprinting may play a role in the etiology of Prader-willi syndrome. Hum. Genet. 88: 42-48.

Groden, J., Nakamura, Y. and German, J. 1990. Molecular evidence that homologous recombination occurs in proliferating human somatic cells. Proc. Natl. Acad. Sci. U.S.A. 87: 4315-4319.

Hansen, M. F., Koufos, A., Gallie, B. L., Phillips, R. A., Fodstad, ø, Brogger, A., Gedde-Dahl, T. and Cavenee, W K. 1985. Osteosarcoma and retinoblastoma: A shared chromosomal mechanism revealing recessive predisposition. Proc. Natl. Acad. Sci. U.S.A. 82: 6216-6220.

Heneen, W. K. and Nichols, W. W. 1972. Nonrandom arrangement of metaphase chromosomes in cultured cell of the Indian deer (Muntiacus muntjak). Cytogenetics 11: 153-164.

Huskins, C. L. 1948. Segregation and reduction in somatic tissues I. Initial observations on Allium cepa. J. Hered. 39: 311-325.

James, C. D., Carlbom, E., Nordenskjold, M., Collins, V. P. and Cavanee, W. K. 1989. Mitotic recombination of chromosome $\# 17$ in astrocytomas. Proc. Natl. Acad. Sci. U.S.A. 86: 2858-2862.

Knudson, A. G., Jr. 1971. Mutation and cancer: Statistical study of retinoblastoma. Proc. Natl. Acad. Sci. U.S.A. 68 820-823.

- 1977. Genetics and etiology of human cancer. In Adv. Hum. Genet. Editors: H. Harris and K. Hirschorn 8: $1-66$

- 1985. Hereditary cancer, oncogenes and antioncogenes. Cancer Res. 45: 1437-1443.

Kucherlapati, R. 1989. Homologous recombination in mammalian somatic cells. Prog. Nucleic Acid Res. Mol. Biol. 36: $301-310$.

McKusick, V. A. 1992. Mendelian Inheritance in Man. John Hopkins Univ. Press Baltimore, pp. 1169.

Mehra, P. N. 1986. Induced mitotic reductions in root tips IV. Concluding remarks. Cytologia 51: 467-472.

- and Dhiman, N. 1986a. An induced meiotic reduction in root tips I. Effect of purine derivatives. Cytologia 51: 439448.

- and - 1986b. Induced meiotic reduction in root tips II. Effect of purine derivatives (contd.) and DNA. Cytologia 51: $449-456$.

- and Kumari, L. 1986. Induced meiotic reductions in root tips III. Effect of pyrimidine derivatives and RNA. Cytologia 51: $457-466$. 
Mitelman, F. 1991. Catalog of Chromosome Aberrations in Cancer, I, II. Wiley-Liss, N.Y. pp. 1987.

Mosgoler, W., Leitch, A. R., Brown, J. K. M. and Heslop-Harrison, J. S. 1991. Chromosome arrangements in human fibroblasts at mitosis. Hum. Genet. 88: 27-33.

Muller, H. G. 1940. An analysis of the process of structural change in chromosome of Drosophila. J. Genet. 40: 166.

Murphee, A. L. and Benedict, W. F. 1984. Retinoblastoma: clues to human oncogenes. Science 223: $1028-1030$.

Nowell, P. C. and Hungerford, D. A. 1960. A minute chromosome in human chronic granulocytic leukemia. Science 132: 1497.

Orkin, S. H., Goldman, D. S. and Sallan, S. E. 1984. Development of homozygosity for chromosome 11p markers in Wilm's tumours. Nature 309: 172-174.

Pontecorvo, G. and Kafer, E. 1958. Genetic analysis based on mitotic recombination. Advances Genet. 10: 71-104.

Quraish, H. B. and Faruqi, S. A. 1979. Cytogenetics of Cymbopogon species from Pakistan. Caryologia 32: $311-327$.

Radman, M. and Kinsella, A. R. 1980. Chromosomal events in carcinogenic initiation and promotion: implications or carcinogenicity and cancer prevention strategies. IARC Scientific Publications. 27: 75-90.

Reeve, A. E., Housiaux, P. J., Gardner, R. J. M., Chewings, W. E., Grindley, R. M. and Millow, L. J. 1984. Loss of a Harvey ras allele in sporadic Wilm's tumour. Nature 309: 174-176.

Riley, R. and Chapman, V. 1958. Genetic control of the cytologically diploid behavior of hexaploid wheat. Nature 182: $713-715$.

Rowley, J. D. 1989. Cancer is a genetic disease. Adv. Oncology 5: 3-8.

Sager, R. 1989. Tumor suppressor genes: The puzzle and the promise. Science 246: 1406-1411.

Schroeder, T. M. and German, J. 1974. Bloom syndrome and Fanconi anemia: Demonstration of two distinct patterns of chromosome distribution and rearrangement. Humangenetik. 25: 299-306.

Scrable, H. J., Witte, D. P., Lampkin, B. C. and Cavenee, W. K. 1987. Chromosomal localization of the human rhabdosarcoma locus by mitotic recombination mapping. Nature 329: 645-647.

Seizinger, B. R., Martuza, R. L. and Gusella, J. F. 1986. Loss of genes on chromosome 22 in tumorigenesis of human acoustic neuroma. Nature 322: 644-647.

Sharma, A. K. and Sharma, A. 1959. Chromosomal alterations in relation to speciation. Bot. Rev. 25: 514-544.

Stern, C. 1936. Somatic crossing over and segretation in Drosophila melanogaster. Genetics 21: 625-630.

Stevens, N. M. 1907. The chromosomes of Drosophila ampelphila. Proc. VII int. Congress Zool. 1912.

- 1908. A study of germ cells of certain Diptera, with reference to the heterochromosomes and the phenomenon of synapsis. J. Exp. Zool. 5: 359-374.

Upcroft, P., Carter, B. and Kidson, C. 1980. Analysis of recombination in mammalian cells using SV40 genome segments having homologous overlapping termini. NARes. 8: 2725-2736.

Volkert, F. C. and Young, C. S. H. 1983. The genetic analysis of recombination using adenovirus overlapping terminal DNA fragments. Virology 125: 175-193.

Wake, C. T. and Wilson, J. H. 1979. Simian Virus 40 recombinants are produced at high frequency during infection with genetically mixed oligomeric DNA. Proc. Natl. Acad. Sci. U.S.A. 84: 9252-9256.

- 1980. Defined oligomeric SV40 DNA: A sensitive probe of general recombination in somatic cells. Cell 21: 141148 .

Welter, D. A., Gatz, A. J. and Smith, W. S. Jr. 1967. Somatic crossover in Klinefelter's syndrome. Lancet ii: 725-726.

Whang-Peng, J., Kao-Shan and Lee, E. C. 1982. Specific chromosome defect associated with small-cell lung cancer: deletion 3p(14-23). Science 215: 181-182.

Wilson, G. B. and Cheng, K. C. 1949. Segregation and reduction in somatic tissue II. The separation of homologous chromosomes in Trillium sp. J. Hered. 40: 3-6.

Woodage, T., Prasad, M., Dixon, J. W., Selby, R. E., Romain, D. R., Columbano-Green, L. M., Graham, D., Rogan, P. K., Seip, J. R., Smith, A. and Trent, R. J. 1994. Bloom syndrome and maternal uniparental disomy for chromosome 15. Amer. J. Hum. Genet. 55: 74-80.

Yokota, J., Wada, M., Shimosato, V., Terada, M. and Sugimura, T. 1987. Loss of heterozygosity on chromosome 3 , 13, 17 in small-cell carcinoma and on chromosome 3 in adenocarcinoma of the lung. Proc. Natl. Acad. Sci. U.S.A. 84: 9252-9256. 